\title{
Regulating Drug Prices: Where Do We Go from Here?
}

\author{
NICHOLAS BLOOM and JOHN VAN REENEN*
}

\begin{abstract}
This paper examines the arguments for changing the ways that UK drug prices are regulated. In the UK, NHS pharmaceutical expenditures on branded drugs, currently worth about $£ 3$ billion a year, have been regulated by the Pharmaceutical Price Regulation Scheme (PPRS) since 1978. We argue that, in publicly funded healthcare systems, pharmaceutical price regulation is necessitated by a tendency towards excessive government expenditure because of over-prescription and the monopoly power of firms with on-patent drugs. We briefly explain the operation of the PPRS, which is based on rate-of-return regulation, and discuss its merits and drawbacks. We then consider five alternative pricing systems: free pricing, therapeutic benefit pricing, international reference pricing, therapeutic reference pricing and RPI $-X$ price regulation. However, we reject all these alternatives in favour of a reformed PPRS. We suggest three potential reforms of the PPRS: an RPI $-X$ cost allowance if feasible or a widening of the rate-of-return bands otherwise; the introduction of a marketing innovation allowance; and greater regulatory transparency.
\end{abstract}

JEL classification: L5, L6, D4.

\section{INTRODUCTION}

Controlling the price of drugs is a major issue on the policy agenda of most modern governments. The reasons are clear. On the one hand, modern states are generally assumed to have a duty to provide at least a minimum level of healthcare services for their citizens. The costs of these healthcare services

*Institute for Fiscal Studies. John van Reenen is also at University College London and the University of California, Berkeley.

The authors would like to thank Karen Bloor, Mike Drummond, Panos Kavanos, Richard Murray, Frank Windmeijer, numerous representatives from the pharmaceutical industry, two anonymous referees and participants at seminars at the London School of Economics, University College London and York for helpful comments. Funding for this project is from the Economic and Social Research Council. 
appear to be inexorably rising due to the combination of an ageing population, technological advances in medical science and the brute fact that health (like education) is a normal good - something that people want to devote increasingly more of their income to, the richer they get. On the other hand, British voters have appeared reluctant to elect parties committed to increased taxation to pay for higher healthcare (Dilnot, 1996). One solution to this situation would be to make patients pay a greater proportion of the costs of healthcare by moving towards a US-style insurance-based system. But British citizens seem highly reluctant to move towards any further 'privatisation' of the NHS.

In the face of this dilemma, cutting pharmaceutical prices to reduce the drugs bill seems very tempting. In fact, over the last decade, expenditure on drugs has risen by about 10 per cent a year, and, in 1995-96, the total bill for NHS pharmaceutical drugs stood at over $£ 5$ billion, about $£ 3$ billion of which went on branded pharmaceuticals covered by the Pharmaceutical Price Regulation Scheme (PPRS) (Office of Health Economics, 1997). Since the current PPRS agreement on drug pricing is in the final year of its five-year term, there have been calls for deep price cuts.

To add to these budgetary pressures on prices, there is also the urgent matter of international price regulation. In a globalised market, there is a constant temptation for small countries to free-ride (by having low prices) on the implicit subsidy given to pharmaceutical R. \& D. by other countries that have higher prices. Since UK sales account for only 3 per cent of global pharmaceutical sales, the UK could potentially drastically cut prices and free-ride on the incentives to undertake R. \& D. provided by higher prices in the US and parts of Europe. However, as a result of the UK's global prominence in the pharmaceutical industry, dramatic price reductions in the UK could precipitate a bout of price-cutting by foreign regulators.

The debates over regulatory reform tend to be highly arcane, and the purpose of this article is to clarify the issues for non-specialists. In Section II, the rationale for pharmaceutical price control is discussed, whilst, in Section III, the current UK PPRS regulatory scheme is evaluated. In Section IV, five alternatives are considered but are ultimately rejected in favour of a reformed PPRS. Section $\mathrm{V}$ discusses in more detail our potential reform proposals, and the final section offers some conclusions.

\section{THE RATIONALE FOR PHARMACEUTICAL PRICE REGULATION}

In order to analyse the requirements of a pharmaceutical pricing scheme, we first need to identify whether we need any price regulation at all. What distinguishes the market for pharmaceutical products from any other market and creates the need for price regulation? 
The fundamental feature of the health market in the UK and most other countries is that consumers generally do not choose or pay for the goods they consume. Even in countries such as the US where the burden of buying health insurance is passed on to individuals, it is still doctors who decide on the appropriate treatment and insurance companies which pay the particular costs. There have been various reforms to make individuals more sensitive to the costs of healthcare in the UK - for example, cost-sharing through prescription charges. These charges do not reflect the relative prices of drugs, however, and in any case most prescriptions are still free. Other moves have included reducing the number of medicines that are allowed to be prescribed (the 'limited list' specifies medicines that are available on paid prescription) and encouraging the further development of private healthcare. It is highly unlikely that Britain will move to a system where individuals bear the primary responsibility for paying directly for their healthcare in the near future. Although patient welfare is at the heart of the health system, the key agents who decide what healthcare services are provided to patients will remain the doctors.

\section{To Regulate the Balance between Patient Care and Government Expenditure?}

The provision of drugs by the NHS suffers from a classic principal-agent problem. The government (the principal) would like doctors (its prescribing agents) to prescribe in a cost-effective manner by evaluating every drug prescription on the basis of a budgetary cost versus therapeutic benefit trade-off. The therapeutic benefit is enjoyed by the individual as a patient; but the budgetary cost is paid for by the individual (and his or her family) as a past, present or future taxpayer. Ideally, only those drugs that could demonstrate therapeutic value for money would be prescribed, ${ }^{1}$ and not otherwise. Doctors, however, are trained to treat illness, operate according to the principles of the Hippocratic oath and are in the front line of the provision of healthcare. As a result, it is not surprising that they are far more likely to be concerned with patient welfare than with ensuring value-conscious prescribing. This will result in the phenomenon of over-prescribing because doctors will not fully balance the costs of additional prescriptions against their therapeutic benefits.

In addition, since doctors are likely to have only a limited concern for expenditure control and generally lack comprehensive information on drug prices (not least because prices can change weekly), they are relatively unresponsive to price changes. This appears to be borne out by studies on prescribing behaviour (Audit Commission, 1994 and 1995; Baines, Whynes and Tolley, 1997). Since monopolists set higher prices for consumers who are more

\footnotetext{
${ }^{1}$ This is more easily stated than applied. No one would disagree that a therapeutically equivalent cheaper drug should be prescribed. But how does one balance an extra pound of expenditure with an increase in the quality of an individual's life?
} 


\section{Fiscal Studies}

price-insensitive, in the absence of price regulation pharmaceutical firms will presumably charge very high prices for their on-patent drugs. The combination of the over-prescription effect and a high free market price would lead to socially excessive expenditure in the absence of price regulation.

\section{To Regulate the UK's Contributions to Global R. \& D. Costs?}

Pharmaceutical sales in the UK only account for about 3 per cent of the world market. ${ }^{2}$ As a result, a cut in the prices of pharmaceutical drugs in the UK should have only a minor effect on the global returns to R. \& D. investment into new drugs. However, if sufficient numbers of countries cut their pharmaceutical prices, this could seriously damage the innovative ability of the industry globally. It is possible that, because the UK is the world's third largest exporter of pharmaceutical drugs, global prices may be particularly sensitive to UK prices. If so, any drastic price cut in the UK could provide a cue for retaliatory price-cutting by regulators in other countries (Danzon, 1997). If British regulators decided to introduce large price cuts, this could provide sufficient provocation for US and European regulators to follow suit. In addition, Table 1 demonstrates that UK prices actually feed directly into the prices of many other European countries. This is because the UK price is a key ingredient in other countries' reference pricing schemes. This creates an additional channel for UK prices to influence global prices. Thus dramatic reductions in the UK price of pharmaceuticals could damage the long-run success of the UK pharmaceutical industry via their effect on international prices.

TABLE 1

Pricing Regimes in Other OECD Countries, 1996

\begin{tabular}{l|l}
\hline Main pricing regime $^{a}$ & \multicolumn{1}{c}{ Country } \\
\hline International reference pricing & Austria, ${ }^{\mathrm{b}}$ Canada, Greece, ${ }^{\mathrm{c}}$ Ireland, Italy, \\
(with UK included in reference basket) & Luxemburg, ${ }^{\mathrm{b}}$ Netherlands, Portugal ${ }^{\mathrm{b}}$ \\
Therapeutic benefit & Belgium, France, Sweden \\
Therapeutic reference pricing & Germany \\
Free pricing & US \\
Cost mark-ups & Spain \\
\hline
\end{tabular}

${ }^{a}$ We classify countries by the pricing mechanism that most accurately approximates their regime, although in practice they implement schemes that may vary across drugs and combine elements from many of the various regimes listed.

${ }^{\mathrm{b}}$ If UK is the country of origin for the product.

${ }^{\mathrm{c}}$ Uses the three lowest EU prices.

Sources: Burstall, 1997; Attridge, 1995; Kavanos, 1998.

${ }^{2}$ Department of Health, 1996. For example, Glaxo-Wellcome estimates that only 8 per cent of its revenues come from UK sales. 


\section{To Regulate the Activities of a Monopolist?}

Pharmaceutical firms hold monopoly power over the supply of particular drugs by virtue of their patents. However, this monopoly control is explicitly granted by the patent system to reward innovation. The patent system attempts to get the right balance between the demands of the consumers for rapid and cheap dissemination of drugs and the need to provide a profit incentive for producers to discover the drugs in the first place. There may be times when there are huge pressures to reduce the patent rights of a company (for example, through compulsorily licensing a life-saving drug), but if this happens there can be little doubt that the incentive to conduct R. \& D. is thereby reduced. The fact that pharmaceutical firms are monopolist providers of their on-patent drugs does not completely release them from the rigours of competition. There is competition at the R. \& D. stage as companies energetically try to leap-frog the current technology with a new product innovation. There is also competition from generics (chemically identical off-patent drugs) when a patent expires. In the US, for example, Griliches and Cockburn (1995) show that generics typically sell for $30-50$ per cent below the branded equivalent and that it is not unusual for a generic to achieve a 50 per cent market share within a year of the patent expiring. Hence, although profits are high in the industry and there is monopoly power, this by itself is not a compelling argument for price regulation.

\section{THE CURRENT PPRS: AN EVALUATION}

The Pharmaceutical Price Regulation Scheme has regulated pharmaceutical prices since 1978. The scheme influences the price of branded drugs but allows complete freedom of pricing of non-branded (generic) drugs. The system is unlike almost any other form of price regulation adopted by UK regulators, and is actually somewhat of a misnomer, being a complicated form of rate-of-return regulation. The complexity of the scheme is illustrated by the following candid statement by Brian Mawhinney, the former Minister for Health, to a House of Commons Select Committee on Health: 'the PPRS is inordinately complicated and I make it clear to the Committee that I would never take it as my question on Mastermind'. This section provides a broad summary of the PPRS and we direct the enthusiastic reader to the fuller explanation of the scheme provided by the PPRS document and the PPRS reports to Parliament (Department of Health, 1993, 1996 and 1997).

Under the PPRS, firms are prevented from raising the prices of existing drugs without the Department of Health's permission, but they are allowed to price new drugs freely subject to their total profit constraint. This constraint is defined as a rate of return on their total NHS capital stock:

PPRS profits $=\alpha \times$ Allowable capital stock 
TABLE 2

Aggregate PPRS Capital, Sales, Costs and Profits for Return-on-Capital Companies, ${ }^{\text {a }} 1994$

\begin{tabular}{l|rr}
\multicolumn{2}{c}{} & Million pounds \\
\hline Home capital employed & Company's initial report & Negotiated out-turn \\
Home sales & 2,422 & 1,935 \\
Sales promotion & 2,646 & 2,646 \\
R. \& D. & 252 & 192 \\
Other costs & 641 & 521 \\
Total costs & 1,718 & 1,553 \\
Total profits & 2,610 & 2,266 \\
Repayments & 35 & 380 \\
Residual profit & & 29 \\
Return on capital & $1.4 \%$ & 350 \\
a Companies whose sales-capital ratio is greater than 3.75 are regulated on a return-on-sales instead of a \\
return-on-capital basis. These firms account for around 10 per cent of total NHS sales and represent those \\
firms that do not have major production facilities in the UK. \\
Source: Department of Health, 1997.
\end{tabular}

where $\alpha$ is the firm-specific target rate of return. This target rate of return lies within a band of 17-21 per cent, with each firm's precise level of $\alpha$ dependent on the Department of Health's view of each company's degree of innovativeness and its commitment to the UK. Around these target rates of return, there is a 25 per cent 'margin of tolerance' within which a firm's returns can fall without it being required to take any corrective action. If a firm's return is above this tolerance band, however, then it must cut drug prices or refund the surplus to the Department of Health. If its rate of return falls below this tolerance band, then the firm can apply for price increases.

In determining profits, the PPRS allows, on aggregate, the expensing of R. \& D. expenditure of up to about 20 per cent of sales. This is above the industry's global R. \& D. intensity of about 11 per cent, ${ }^{3}$ and so can be considered generous towards R. \& D. Expensing of sales promotion activities from profits of up to 9 per cent of sales is also allowed. This appears to be significantly less than the levels of our main competitors for which estimates are available, ${ }^{4}$ suggesting that the PPRS is less than generous towards marketing activities.

Table 2 presents figures on the operation of the scheme. It contains aggregate information on the figures that firms initially report to the Department of

${ }^{3} \mathrm{OECD}, 1997$

${ }^{4}$ Department of Health, 1996. 
Health's PPRS team and the out-turns that are arrived at through negotiation. The negotiation process involves the Department of Health attempting to validate the figures provided by the pharmaceutical firms and moving from their initial claims to a figure the Department views as more realistic. For example, as a result of this negotiation process, the figure for the aggregate return on capital is raised from the 1.4 per cent level that the firms initially reported to the negotiated 18.1 per cent after repayments. It would be of great interest to know in more detail the arguments involved in such a substantial disagreement of opinion between the agents of industry and the state but, because of the secrecy surrounding the PPRS (see below), it is impossible to judge how reasonable the final numbers are.

\section{Arguments for Abandoning the Current PPRS}

There are three main criticisms of the PPRS: it allows excessively high prices, it generates little incentive to cut costs and it lacks transparency. We examine each in turn.

\section{(a) The PPRS Allows Excessively High Prices}

Under the PPRS, the pharmaceutical budget has risen by around 10 per cent a year for the last two decades. ${ }^{5}$ This has led to the criticism that the PPRS is too soft on drug prices. One way to evaluate this claim would be to undertake international comparisons of pharmaceutical prices. However, constructing international price comparisons is fraught with problems of defining appropriate samples, calculating sample weighting, making exchange rate adjustments and comparing different pack and pill sizes (Attridge, 1995). As a result of these methodological difficulties, studies often disagree on the exact position of the UK in the international ranking between countries. In general, however, most countries can be reasonably classified into one of three groups (Table 3), with the UK in the group of countries with intermediately priced drugs.

TABLE 3

Pharmaceutical Price Comparisons for a Sample of Countries

\begin{tabular}{l|l}
\hline High-price countries & US \\
$\begin{array}{l}\text { Intermediate-price countries } \\
\text { Low-price countries }\end{array}$ & $\begin{array}{l}\text { Denmark, Germany, Ireland, Netherlands, UK } \\
\text { France, Greece, Italy, Portugal, Spain }\end{array}$ \\
\hline $\begin{array}{l}\text { Source: Based on price comparisons from Burstall (1997), Department of Health (1993, } 1996 \text { and 1997), } \\
\text { Mossialos (1997) and Reekie (1997). }\end{array}$
\end{tabular}

${ }^{5}$ Office of Health Economics, 1997. 


\section{Fiscal Studies}

When considering this evidence to justify price cuts, one should also bear in mind the comments made in Section II about the strength of the UK's pharmaceutical industry and her potentially pivotal position in global pricing. Thus we cannot conclude that curbing excessively high prices provides sufficient justification for reforming the PPRS.

\section{(b) The PPRS Provides Little Incentive to Cut Costs}

A major criticism of the PPRS is that it provides weak incentives for firms to control costs. This is a general feature of rate-of-return regulation. If cost improvements are passed straight through into lower prices, there is little reward for managers expending time and effort in cutting costs. This leads to phenomena such as the 'export disincentive', whereby firms are penalised with lower NHS prices if they increase their capital productivity and export the surplus, or (potentially) the Averch-Johnson effect (Averch and Johnson, 1962), whereby firms choose an inefficiently high capital stock in order to increase their allowable capital base. The Department of Health is well aware of the potential for inefficient production and states in the PPRS document (Department of Health, 1993) that only 'reasonable costs of production' are allowed to be expensed. It has two mechanisms at its disposal to estimate the level of reasonable costs, but both of these suffer from problems of asymmetric information.

One approach involves undertaking yardstick comparisons between UKbased pharmaceutical firms. However, there are reasons to doubt the efficacy of yardstick comparisons when applied to the UK pharmaceutical industry. First, the production processes for different drugs are not easily comparable, and patented drugs, which the PPRS mainly regulates, are generally produced by only one firm. Second, as with any form of yardstick comparisons applied to a small number of firms, one might expect the UK pharmaceutical industry to appreciate the zero-sum nature of cost-cutting exercises and the benefits from tacitly agreeing not to pursue cost reductions too vigorously. ${ }^{6}$ These problems can be addressed to some extent by the comparison with each firm's international production cost data, such as those published in its annual accounts, although once again problems of comparability and distortion of information will occur.

Another approach to estimating reasonable production costs involves comparing current costs with those in previous years for each firm. However, the use of past performance comparisons can create a negative ratchet effect. Firms may appreciate that cost reductions achieved in the current period will be translated into demands for lower costs in future years. This provides the firm

${ }^{6}$ This is quite consistent with there being vigorous competition in other areas, such as R. \& D. activities. 
with a large incentive not to reveal information on its current costs because of the fear that this will be translated into tougher requirements in the future.

Because of the difficulty of the Department of Health's task in estimating reasonable costs, it would appear that the PPRS provides only limited incentives for firms to control costs. ${ }^{7}$

\section{(c) The PPRS Lacks Transparency}

Numerous commentators, including the Parliamentary Health Committee, ${ }^{8}$ have expressed their concern over the secrecy surrounding the PPRS. The secrecy prevents effective evaluation of the scheme, leads to the suspicion of regulatory capture and increases uncertainty - an entry barrier to potential new entrants. The recent provision of information in the Department of Health reports to Parliament (1993, 1996 and 1997) on the workings of the PPRS has, however, improved the awareness and transparency of the system. Nevertheless, major decisions are still arrived at by a process of negotiation and the mechanics and results of these negotiations are generally kept secret. For example, the process by which the Department of Health negotiates up the aggregate rate-of-return figures from 1.4 per cent to 18.1 per cent (see Table 2) is confidential but of crucial importance to the operation of the PPRS.

\section{Reasons for Keeping the Current PPRS}

Against these criticisms, defenders of the PPRS point out its three main advantages: stability, flexibility and its role in promoting the UK pharmaceutical industry.

\section{(a) The PPRS Provides a Stable Regulatory Environment}

The regulatory literature emphasises the importance of creating a stable regulatory environment in promoting long-term investment. ${ }^{9}$ If incumbent firms believe that, once they have finished their investment projects, regulators will drastically cut prices, they may decide not to invest in the first place. That is, the fear of being 'held up' by the regulator will play an important role in determining the level of long-term investment undertaken by any regulated firm. These issues are particularly relevant to the pharmaceutical industry because of

\footnotetext{
${ }^{7}$ One response to this criticism, however, is that many UK pharmaceutical firms also produce drugs for the export market in their UK production plants. These markets provide firms with an incentive to cut costs since foreign regulatory regimes do not provide allowances for UK costs. Since the PPRS allocates costs more or less pro rata with capital stock, the incentive to cut costs will be proportional to the export ratio. But, since only about a half of aggregate UK pharmaceutical production is exported (Department of Health, 1997), the incentives to cut costs will still be limited.

${ }^{8}$ Department of Health, 1994.

${ }^{9}$ For example, Armstrong, Cowan and Vickers (1994) and Laffont and Tirole (1994).
} 


\section{Fiscal Studies}

the long-term nature of the returns to R. \& D. ${ }^{10}$ By creating a stable regulatory environment, the PPRS helps to encourage pharmaceutical firms to undertake investments into new drugs and more efficient production facilities. The PPRS has helped to maintain a stable regulatory regime over the last 20 years. This will have generated a body of 'reputational capital', which will make it more reputationally costly for the government to introduce drastic reforms, and so would reduce the industry's concerns over such moves if the PPRS were to be continued. But, in addition, the fundamental characteristics of the PPRS system itself are also important in generating stability - in particular, the five-year life of agreements, the participation of the industry in negotiating the agreements and the three-year targets for allowable R. \& D. expenditure (Mossialos, 1997).

\section{(b) The PPRS is a Flexible Regulatory Regime}

The PPRS has a proven track record in adapting to a wide variety of firms over a 20 -year period. This is against the backdrop of significant changes in the nature of public healthcare in the UK with, for example, the introduction of the NHS internal market. As a tried and tested pricing regime that appears robust to significant institutional change, there would clearly be advantages in maintaining the current PPRS for any government intent on further major reforms of the NHS, as the current government appears to be. Furthermore, the PPRS can be advocated on its track record of a relatively speedy introduction of new drugs to the NHS and the additional benefits this provides to patients.

\section{(c) The PPRS Promotes the UK Pharmaceutical Industry}

Although it seems somewhat strange to argue that price regulation could assist an industry's development, the PPRS has been proposed as a candidate for engendering the impressive track record of the UK pharmaceutical industry (Thomas, 1994; Bloom and van Reenen, 1997). One explanation is that pharmaceutical R. \& D. may have, at least historically, displayed domestic spillovers. By providing generous R. \& D. expensing allowances, the PPRS could have encouraged a more socially optimal level of R. \& D. investment. Another potential reason is that, by allowing for a generous rate of return, the PPRS provided sufficient profits to obviate the problems of external financing, which can be particularly acute for R. \& D. investment. In addition, due to the provision of a more generous rate of return on domestic than overseas capital stock, the PPRS has also provided an incentive for firms to switch production and R. \& D. facilities to the UK. Finally, industry representatives also cite the stability of the PPRS regulation over the last 20 years as an important factor behind the UK's pharmaceutical success, as outlined above.

${ }^{10}$ On average, it takes over 10 years for a product to come to market from the initiation of the research project (Grabowski and Vernon, 1994). 
However, whilst the PPRS may have helped to foster the conditions necessary to create a successful UK pharmaceutical industry, there are clearly other important factors behind this success, such as the strong university tradition of biomedical research, the role of the NHS and the early introduction of efficacy regulation. Furthermore, because of the multinational nature of the UK's largest pharmaceutical firms and the global nature of today's markets, the PPRS plays a less important role now than it did historically. ${ }^{11}$

None of these counter-arguments seems an adequate rebuttal of the critique of the PPRS. But do the alternatives provide a more desirable approach to pharmaceutical price regulation?

\section{ALTERNATIVE PRICING SCHEMES: FIVE OPTIONS}

We consider five alternative pricing schemes which have been adopted in other European countries, adopted in the regulation of UK utilities or suggested by industry commentators. Although this list is not an exhaustive survey of all the potential alternatives, we believe it includes any regulatory system (or minor variant thereof) that merits further consideration.

\section{Alternative 1: Free Pricing}

Complete freedom of pricing is favoured by many drugs firms and is equivalent to the essentially deregulated US solution. It would save administrative costs and eliminate regulatory distortions. The need for price regulation, arising from doctors' incentives to over-prescribe and their limited price sensitivity, was discussed in Section II. There have been a raft of reforms in Britain aimed at improving the sensitivity of doctors to drug prices. GP fundholding and the PRODIGY system ${ }^{12}$ are two important examples. Although in the US healthcare maintenance organisations (HMOs) have gone even further down this route, the existing empirical evidence in Britain suggests that the increase in price sensitivity has been limited (for example, Baines, Whynes and Tolley (1997)).

One apparent argument in favour of free pricing is that when doctors are cash-limited, as they may soon be, price regulation could be relaxed since cash limits provide an alternative mechanism to restrict the growth of the drugs budget. However, even if the total level of NHS sales is fixed, individual drugs firms will still wish to maximise their share of this budget. Since doctors do display low price sensitivities, each firm will still face an incentive to raise its

\footnotetext{
${ }^{11}$ For example, Adams and Jaffe (1996) find that geographical proximity of innovators is much less important in pharmaceuticals than in other parts of the US chemical industry.

${ }^{12}$ This is a piece of software used by doctors to tap into a database that gives instant information on the lowestcost drug that is therapeutically equivalent to the one the doctor intends to prescribe.
} 


\section{Fiscal Studies}

prices closer to the monopoly price for on-patent drugs. The resultant outcome could be significantly higher drug prices (as occur in the US), which, given a fixed budget, would require swingeing cuts in the levels of pharmaceuticals prescriptions. This is neither politically nor economically desirable, even if it were possible.

\section{Alternative 2: Therapeutic Benefit Pricing}

Under therapeutic benefit pricing, a panel of doctors adjudicate over the therapeutic benefits patients receive and set prices accordingly (i.e. higher prices for the most beneficial drugs). ${ }^{13}$ This system has the advantage that it correctly addresses the incentives for firms to develop socially beneficial drugs. The more effective a drug and the wider the target group, the greater the value it provides to society. Setting prices in relation to therapeutic benefits leads to a direct relationship between profits and social value, providing incentives for firms to undertake R. \& D. that they believe will be socially beneficial. Thus therapeutic benefit pricing provides incentives for dynamic efficiency - maximising the expected social value of any outlay on R. \& D.

In maximising social welfare, however, there are two general efficiency components that could be targeted by a price regulation system (Mayer and Vickers, 1996). The first objective is productive efficiency, which involves firms producing pharmaceuticals in a cost-effective manner. For example, one component of productive efficiency is the determination of the correct level of R. \& D., since R. \& D. is an input into the dynamic production process. The second objective of price regulation is allocative efficiency, which involves doctors allocating pharmaceuticals in an efficient manner. By prescribing drugs only when their therapeutic benefit outweighs their production cost, allocative efficiency can be obtained. The problem with any pricing system is that, with only one instrument (the price), it is not possible for the regulator to simultaneously meet two objectives (productive efficiency and allocative efficiency).

By targeting dynamic efficiency, therapeutic benefit pricing provides incentives for the efficient use of R. \& D. by firms but provides no incentives for allocative efficiency on the part of doctors. In most European countries, it will not be possible to target allocative efficiency with prices, since doctors will not respond to price changes. Hence adopting a pricing scheme, such as therapeutic benefit pricing, that targets dynamic efficiency appears entirely rational. In contrast, UK doctors have been provided with incentives to prescribe in a price-

\footnotetext{
${ }^{13}$ For example, prices could be set as some linear function of quality-adjusted life years. Drummond, Jonsson and Rutten (1997) undertake a comprehensive discussion of economic evaluations in drug pricing.
} 
sensitive manner and do display some, albeit limited, price sensitivity. Thus price regulation has the option of targeting allocative efficiency or dynamic efficiency or some combination of both. As discussed earlier, since the UK only accounts for around 3 per cent of the global market, UK prices will have only a small impact on the dynamic incentives of globalised firms, making UK prices a weak instrument for targeting dynamic efficiency. On the other hand, to the extent that doctors display some form of price sensitivity, prices can target allocative efficiency. So, if doctors do display price sensitivity and the government is intent on encouraging this, adopting therapeutic benefit pricing will ignore one targetable objective of price regulation.

In addition, there are substantial difficulties in systematically determining the therapeutic values of drugs, and such a process could leave the regulator open to legal challenge. Hence we do not advocate therapeutic benefit pricing as either a desirable or an easily achievable alternative for the UK. In other European countries, therapeutic benefit pricing would be a reasonable option if the domestic market were large enough to have an impact on global R. \& D. and if governments had no intentions to encourage doctors to prescribe in a pricesensitive manner.

\section{Alternative 3: International Reference Pricing}

An approach adopted by a number of European countries is reference pricing based on a weighted average of other countries' drug prices. Under this scheme, regulators need only to choose the group of countries in the basket, ${ }^{14}$ set the weights on each country and adjust for exchange rate movements. This scheme has the advantage that it is administratively simple and, depending on the basket of countries, can provide prices that lie in the middle of some international price span.

International reference pricing, however, is not really a separate and wholly alternative type of price regulation. Instead, it reflects an average of pricing systems in the comparator basket of countries. Since these pricing systems can presumably be ranked on some desirability basis, it would be preferable to choose the most desirable pricing system and place 100 per cent weight on it. Going one step further, once a foreign pricing system has been chosen, it would seem undesirable to leave domestic prices under the control of a foreign regulator and exposed to exchange rate changes. This foreign system could be adopted in the UK and perfected for the UK healthcare environment. Thus reference pricing is just a mechanism to side-step the pharmaceutical price

\footnotetext{
${ }^{14}$ This in itself actually provides a wide degree of latitude over the generosity of the pricing scheme, due to the large international price variations.
} 


\section{Fiscal Studies}

regulation debate by avoiding making any rational choice and instead taking an average of all the systems in the basket as applied by foreign regulators. On this basis, international reference pricing is not a real alternative for the UK. ${ }^{15}$

\section{Alternative 4: Therapeutic Reference Pricing}

Another approach adopted by a number of European countries is to class drugs that are therapeutically equivalent into groups and provide government reimbursement only for the cost of the cheapest drug in the group. This should drive prices down towards the lowest price in the group. However, the PPRS does not control the prices of generic drugs for which there exist therapeutic equivalents since competition and reimbursements at the market average price ensure that no additional regulation is required. In fact, the difficulties of regulating pharmaceutical prices concern precisely those drugs for which there is no therapeutic equivalent so that pharmaceutical firms possess significant market power. Therapeutic reference pricing is clearly unable to regulate the prices of these drugs. Thus therapeutic reference pricing does not provide a suitable alternative to the PPRS.

\section{Alternative 5: RPI-X Price Regulation}

RPI $-X$ regulation was first used to regulate British Telecom in 1984 and has since been widely adopted by other regulators in the UK and overseas. As such a tried and tested formula for price regulation, it is an obvious candidate for extension to the pharmaceutical sector as well.

Under RPI $-X$ price regulation, firms would need to ensure that a weighted average of their price increases each year did not exceed the percentage increase in the retail price index less $X$. The $X$ factor could vary from firm to firm but would be fixed between price reviews. It would be reset by the regulator at each regulatory review - every five years, for example - allowing the PPRS department to pass through to the NHS additional cost reductions from pharmaceutical firms.

RPI $-X$ price regulation provides firms with real incentives to cut production costs since, between reset periods, any cost savings feed straight through into profits. In the longer run, by adjusting the $X$ factor to reflect past cost reductions, the regulator can pass these cost savings on to the NHS in the form of lower

\footnotetext{
${ }^{15}$ For a small country with no domestic pharmaceutical industry to promote, however, the incentives would be to charge as low a price as possible consistent with being supplied with drugs. This policy is limited by the potential for parallel importing whereby low prices in one EU country are exported as lower prices in other EU countries. Thus pharmaceutical firms will delay or refuse supply to any EU country whose prices are too out of line with other EU countries (Danzon, 1997). Hence a reference pricing scheme based on the lowest prices in other EU countries where drugs are currently being provided - for example, as approximately adopted by Greece - should enable cost minimisation consistent with the supply of pharmaceuticals.
} 
prices. However, RPI $-X$ pricing, as applied to the pharmaceutical sector, suffers from three potential drawbacks.

First, it is not clear what $X$ factor would be appropriate. On the one hand, a high $X$ factor, leading to a rapid erosion of individual drug prices over time, would provide incentives for firms to continuously withdraw drugs from the market and re-enter them with slight modifications as new drugs but at higher prices. This has been a criticism of price regulation in France, Italy and Japan, where rapid price erosion appears to have led to an excessively high turnover in the drugs market as firms continually withdraw and re-enter drugs (Thomas, 1994). This wastes marketing resources and impedes doctors' pharmaceutical learning ability. On the other hand, a low $X$ factor, implying slow price reductions, may not be consistent with the total constraint on NHS spending if firms are to be allowed the freedom to set their initial prices. Whether both of these constraints on the $X$ factor can be simultaneously satisfied is not clear. For example, an $X$ factor set at 5 per cent might leave prices too high over a drug's life cycle to meet NHS budgetary requirements whilst also reducing prices rapidly enough to encourage firms to excessively churn their drugs portfolios. This leaves some doubt about the feasibility of an RPI $-X$ scheme.

Second, RPI $-X$ pricing was not developed to cope with continuous product innovation as occurs in the pharmaceutical industry. This raises problems over how to introduce new drugs into the price index. Various introductory prices have been suggested, including an initial period of free pricing or setting initial prices at prevailing US levels.

Third, under the PPRS, rapid increases in the volume of drug prescriptions lead to countervailing price reductions to ensure firms stay within their rate-ofreturn limit. Under an RPI $-X$ pricing regime, however, no such overall constraint on NHS expenditure would apply, so that quantity changes would lead straight through into budgetary changes. As a result, the NHS pharmaceuticals budget could potentially be highly unstable and uncontrollable. This problem could be exacerbated if firms increased their marketing activities in recognition of their potential for far higher sales.

\section{REFORM OF THE PPRS}

From the discussion of the PPRS in Section III, it is clear that there are problems with the current system. We suggest three potential reforms to address the perceived problems of cost inefficiency and lack of transparency.

\section{1a. Either: An RPI - X Cost Allowance}

A major shortcoming of the PPRS, as noted above, was the limited incentive for efficient operation. This is an important issue since 'Other costs' account for about 60 per cent of the price of drugs (Table 2). Experience from regulating the 


\section{Fiscal Studies}

utilities suggests that providing appropriate incentives is important when attempting to generate cost reductions. In addition, the cost reductions achieved under the RPI $-X$ pricing of utilities were not fully anticipated ex ante (Trade and Industry Committee, 1996-97). Thus there could ${ }^{16}$ be some reason to expect that, if pharmaceutical firms were also given strong cost-reduction incentives, then drugs costs could also be cut by 10-20 per cent, which would allow for price reductions and an improved provision of drugs to patients under a fixed drugs budget.

One remedy to the PPRS to introduce greater incentives for cost-cutting would be to adopt RPI $-X$ for costs only. Under an RPI $-X$ cost allowance, prices would be set in the standard PPRS manner except that the acceptable outturn for firms' costs would be taken from a predetermined RPI $-X$ index of costs rather than the actual out-turn. If a firm managed to reduce production costs faster than its RPI $-X$ index, it would get to keep the surplus, whilst, in reverse, firms would have to bear the financial impact if their costs rose by more than the index. In this way, firms would be given the same incentives to cut costs as those provided by the more standard RPI $-X$ price regulation. So, to reiterate, the system would operate in an identical manner to the current PPRS except that costs taken into account would not be the actual measured costs but those taken from an RPI $-X$ cost index. Clearly, creating this RPI $-X$ cost index would be a crucial issue. The index would need to calculate a reasonable cost of production for each firm for each possible level of drug production. To do this, the regulators would need to devise a unit cost per drug measure for every drug, of which a simple stylised example is provided in Table 4.

Creating this index would clearly place large informational burdens on the regulators at the end of every five-year period when they needed to reset the index. ${ }^{17}$ However, such a system is not without international parallel. The

TABLE 4

\section{A Stylised Example: RPI $-X$ Cost Allowance for Firm $Z$}

Index for year 1998:

Drug A: $£ 1$ per drug for the first 1,000 units; 50 p thereafter.

Drug B: $£ 5$ per drug for the first 5,000 units; $£ 4$ for the next 10,000 ; $£ 3$ thereafter.

Drug C: $£ 2$ per drug for the first 100 units; $£ 1.50$ thereafter.

Cost allowance in each subsequent year to rise by RPI $-X . X$ set at 6 per cent.

\footnotetext{
${ }^{16}$ There are factors other than regulation that could account for large cost reductions in utilities, such as the change in ownership from the public to the private sector.
} 
Spanish authorities estimate the production costs of drugs on a product-byproduct basis (Kavanos, 1998), the Italians undertook this until 1993 (when it was disbanded following a major corruption scandal), and President Clinton's Health Security Act proposed cost-plus regulation which would have required individual drug production cost estimations (Danzon, 1997). Whether these informational requirements could be met is not clear, in part because of the secrecy surrounding the current information-gathering process under the PPRS. However, if this were achievable, RPI $-X$ costing could address the major drawback of the current PPRS - the lack of incentives for efficient production.

\section{1b. Or: Extending the Rate-of-Return Bands}

If informational shortcomings prevent the introduction of a full RPI $-X$ cost allowance, it would still be highly desirable to increase the incentives for firms to undertake cost-cutting activities. An amendment to the current scheme that would help to achieve this would be a widening of the rate-of-return bands. Under the PPRS, each firm is permitted to deviate by up to 25 per cent from its rate-of-return target. Any returns that fall above this margin of tolerance must be corrected with price changes or rebates. In reverse, any firm whose return falls below the lower limit of the margin of tolerance can seek a price rise.

Widening this margin of tolerance would help to address the lack of incentives to cut costs, because firms would get to keep the benefits from more efficient production over a larger range of returns. Of course, in order to ensure that this scheme did not increase the aggregate PPRS rate of return (and thus prices), the target band could be raised or lowered from its current 17-21 per cent range. This could be achieved so as to maintain a constant average rate of return for the whole industry whilst allowing larger variation between firm performances than under the current PPRS. Since more firms lie above than below their target rates, increasing the band width would probably require a compensating reduction in the central target to ensure that returns remained constant on aggregate. This should improve efficiency levels without any additional budgetary costs, but at the expense of a greater variation in firm returns. However, the current variation of returns allowed under the PPRS is significantly less than those observed for the FT500 on which the target band is based. This suggests that some trade-off between increasing the inequality of returns and lowering drug prices (achieved by efficiency pass-throughs) would be desirable.

\footnotetext{
${ }^{17} \mathrm{New}$ drugs could be costed as they currently are and entered into the RPI $-X$ costing regime only after enough years of data had been built up on them.
} 


\section{Marketing Innovation Allowance}

The current PPRS permits a similar level of marketing expensing (below 9 per cent) across all firms, whatever their marketing needs. All further marketing activity is non-expensable for the PPRS costs calculations. In general, marketing activities that inform doctors of new drugs and trial results should be encouraged as a way of promoting both better prescribing habits and price sensitivity (since one requirement of price sensitivity is well-informed doctors). However, marketing activities that are aimed at promoting one brand of a therapeutic equivalent over another brand should be discouraged, simply because it is, on aggregate, a waste of resources and doctors' time. Thus, whilst informative marketing activities should be expensable, brand-building marketing activities should not be.

One proxy for the necessary level of informative marketing activity would be the share of on-patent drugs in the total portfolio. ${ }^{18}$ So a marketing innovation allowance could attempt to promote informative marketing and discourage brand-building by taking into account each company's shares of on- and offpatent drugs in its PPRS portfolio. For example, the relatively simple marketing expense rule shown below, which would be applied on a firm-by-firm basis, would achieve this whilst maintaining the current 9 per cent aggregate expensing cap:

Firm's marketing expense allowance $=$

Sales $\times 0.09 \times \frac{\text { Firm's share of on }- \text { patent drugs as } \% \text { of all firm's PPRS drugs }}{\text { National average share of on }- \text { patent drugs as } \% \text { of all PPRS drugs }}$.

Alternatively, R. \& D. expenditure levels could be used to proxy for informative marketing needs.

\section{Greater Regulatory Transparency}

Another lesson from the regulation of the utilities is that regulation evolves and improves over time. This partly reflects learning by the regulators themselves but also reflects the positive effect of discussion, research and criticism by external commentators. Greater provision of information by the Department of Health would facilitate a more extensive consideration of the issues, assisting the input into the regulatory debate. In addition to concerns over the evolution of regulation, there is also an issue of accountability, which was highlighted by the Health Committee Session 1993-94 (Department of Health, 1994).

Furthermore, as has been recognised in the regulatory economics literature since Stiglitz (1971), there exists the potential for regulatory capture. This

${ }^{18}$ The PPRS covers all branded drugs, whether they are patented or not, because some firms sell branded generics (off-patent drugs that are prescribed under a brand name). 
suggests that the combination of extensive regulatory discretion, frequent and extended exposure to industry participants, and limited external checks could lead regulators to unduly favour the industry they are regulating. That the PPRS regulatory department meets all these conditions clearly does not make it guilty of regulatory capture. However, it highlights the danger that, even if regulatory capture has not yet occurred, it presents a real danger and will draw continued criticism. For example, it was suggested by the Parliamentary Health Committee ${ }^{19}$ that 'If the scheme does result in an unfair tilting, there are grounds for supposing that this may be in the direction of the industry rather than the NHS'. Greater provision of information would enable outsiders to gauge whether this was a valid concern and allay the suspicions of critics.

The Department of Health does provide some information on the operation of the PPRS, much of which is contained in the annual PPRS reports to Parliament, ${ }^{20}$ but this is very limited in scope, with only a few tables of actual figures on industry aggregates provided. We accept that complete transparency is not realistic due to the need to protect commercially sensitive information and the dynamics of the regulation. However, it would still be desirable to increase the current level of transparency, and, to this end, we advocate the following reforms:

- publishing distributions of firms' targets, reported annual financial returns and negotiated out-turns;

- publishing the frequency of firms reporting results outside their relevant 25 per cent band and the action taken;

- publishing anonymised data close to or at the firm level on targets, annual financial returns and out-turns, where consistent with adequate secrecy. Historical data would still be useful - say, releasing information with a three-year lag — and would present less serious confidentiality problems.

This list is not exhaustive and additional measures to those mentioned above are also discussed by Bloor and Maynard (1997), Caves and Towse (1997) and Mossialos (1997).

\section{CONCLUSIONS}

The provision of pharmaceuticals in publicly funded healthcare systems is affected by informational asymmetries between patients, doctors and the government. This results in both a tendency towards over-prescription and a lack of price sensitivity on the part of doctors. Since the suppliers in the markets do have some temporary monopolies through patents (justified as the reward for

${ }^{19}$ Contained in Department of Health (1994, p. 3).

${ }^{20}$ Department of Health, 1996 and 1997. 


\section{Fiscal Studies}

past R. \& D. efforts), price regulation will be required to curtail pharmaceutical expenditure.

The UK Pharmaceutical Price Regulation Scheme (PPRS) regulates the prices of UK drugs sales to the NHS. The PPRS has been successful at creating a stable and flexible regulatory environment. However, it suffers from a serious drawback in that it provides little incentive for firms to cut costs. In addition, the PPRS has been criticised for lacking transparency. We have considered five alternative price regulation systems: free pricing, therapeutic benefit pricing, international reference pricing, therapeutic reference pricing and RPI $-X$ price regulation. However, we rejected all these radical alternatives. Instead, we propose maintaining the current PPRS but suggest the consideration of three potential reforms, which are:

- the introduction of an RPI $-X$ cost allowance if feasible or the widening of the rate-of-return bands;

- the introduction of a marketing innovation allowance;

- greater regulatory transparency.

An RPI $-X$ cost allowance would provide firms with strong incentives to tackle production costs, which account for about 60 per cent of prices. Given the precedent of large cost reductions in the utilities sector, this could facilitate substantial long-term price reductions. Even if this were not possible, it would still be desirable to create greater incentives for productive efficiency by widening the rate-of-return bands. The second reform - the introduction of a marketing innovation allowance - is aimed at improving the informational content of marketing activities, whilst our final reform - greater regulatory transparency — addresses the need for informational feedback to enable regulation to improve and evolve over time.

\section{REFERENCES}

Adams, J. and Jaffe, A. (1996), 'Bounding the effects of R\&D: an investigation using matched establishment-firm data', Rand Journal of Economics, vol. 27, pp. 700-21.

Armstrong, M., Cowan, S. and Vickers, J. (1994), Regulatory Reform, Cambridge, Mass.: MIT Press.

Attridge, J. (1995), International Comparisons of Pharmaceutical Prices in Europe, British Pharma Group Policy Pamphlet, Uxbridge: British Pharma Group.

Audit Commission (1994), A Prescription for Improvement, London: HMSO.

- (1995), What the Doctor Ordered, London: HMSO.

Averch, H. and Johnson, L. (1962), 'Behaviour of firms under regulatory constraint', American Economic Review, vol. 52, pp. 1052-69.

Baines, D., Whynes, D. and Tolley, K. (1997), 'General practitioner fundholding and prescribing expenditure control', Pharmacoeconomics, vol. 11, pp. 350-8. 
Bloom, N. and van Reenen, J. (1997), 'Why has the UK pharmaceutical industry been successful?', mimeo, Institute for Fiscal Studies.

Bloor, K. and Maynard, A. (1997), 'Regulating the pharmaceutical industry', British Medical Journal, vol. 315, pp. 200-1.

Burstall, M. (1997), 'How do they do it elsewhere in Europe?', in D. Green (ed.), Should Pharmaceutical Price Be Regulated?, London: Institute of Economic Affairs.

Caves, M. and Towse, A. (1997), 'Regulating prices paid by the NHS for medicines supplied by the UK-based pharmaceutical industry', Office of Health Economics, Briefing no. 34.

Danzon, P. (1997), Trade and Price Differentials for Pharmaceuticals: Policy Options, London: Office of Health Economics.

Department of Health (1993), Pharmaceutical Price Regulation Scheme, October, London: Department of Health.

- (1994), Government Response to the Second Report from the Health Committee Session 199394, Cm. 2683, London: HMSO.

- (1996), Pharmaceutical Price Regulation Scheme Report to Parliament, London: Department of Health.

- (1997), Pharmaceutical Price Regulation Scheme Second Report to Parliament, London: Department of Health.

Dilnot, A. (1996), 'The assessment: the future of the welfare state', Oxford Review of Economic Policy, vol. 11, no. 3, pp. 1-10.

Drummond, M., Jonsson, B. and Rutten, F. (1997), 'The role of economic evaluation in the pricing and reimbursement of medicines', Health Policy, vol. 40, pp. 199-215.

Grabowski, G. and Vernon, J. (1994), 'Returns to R. \& D. on new drug introductions in the 1980s', Journal of Health Economics, vol. 13, pp. 389-405.

Griliches, Z. and Cockburn, I. (1995), 'Generics and the producer price index for pharmaceuticals', in R. Helms (ed.), Competitive Strategies in the Pharmaceutical Industry, Washington DC: AEI Press.

Kavanos, P. (1998), 'Single European currency and monetary union: macroeconomic implications for pharmaceutical spending', Pharmacoeconomics, vol. 13, pp. 9-20.

Laffont, J. and Tirole, J. (1994), A Theory of Incentives in Procurement and Regulation, Cambridge, Mass.: MIT Press.

Mayer, C. and Vickers, J. (1996), 'Profit-sharing regulation: an economic appraisal', Fiscal Studies, vol. 17, no. 1, pp. 1-18.

Mossialos, E. (1997), An Evaluation of the PPRS: Is There a Need for Reform?, in D. Green (ed.), Should Pharmaceutical Price Be Regulated?, London: Institute of Economic Affairs.

OECD (1997), Structural Analysis Industrial (STAN) Database, Paris: Organisation for Economic Co-operation and Development.

Office of Health Economics (1997), Compendium of Health Statistics 1997, London: Office of Health Economics.

Reekie, W. D. (1997), The PPRS: Regulations without a Cause?, in D. Green (ed.), Should Pharmaceutical Price Be Regulated?, London: Institute of Economic Affairs.

Stiglitz, G. (1971), 'The theory of economic regulation', Bell Journal of Economics, vol. 6, pp. 321.

Sutton, J. (1997), 'Not by technology alone', mimeo, London School of Economics.

Thomas, L. G. (1994), 'Implicit industrial policy: the triumph of Britain and the failure of France in global pharmaceuticals', Industrial and Corporate Change, vol. 3, pp. 451-89. 


\section{Fiscal Studies}

Trade and Industry Committee (1996-97), First Report: Energy Regulation, HC50-1, London: HMSO. 